\title{
Bohdan Ulašin
}

\section{Los indigenismos iberoamericanos en eslovaco}

Palabras clave: indigenismo, lenguas amerindias, eslovaco, español, creación semántica, cronología

DOI: 10.4312/ars.11.2.104-123

\section{Introducción}

El objetivo de este artículo es presentar la influencia que han tenido las lenguas amerindias en el léxico eslovaco. Para cumplir tal objetivo tuvimos que establecer criterios de inclusión en el corpus, recopilar y analizar los indigenismos en la lengua eslovaca. Aparte de presentar las voces amerindias, quisimos resumir también las tendencias en el proceso de adaptación al eslovaco (haciendo hincapié en los contrastes entre el español como lengua intermediaria y el eslovaco) y también analizar la cronología de la aparición de los indigenismos, centrándonos en los préstamos pioneros (desde los primeros del siglo XVII) y clasificar las entradas del glosario según las áreas temáticas y la lengua amerindia de origen.

\section{Delimitación del objeto del artículo}

Al principio pensábamos incluir solamente los indigenismos hispanoamericanos, pero pronto nos dimos cuenta de lo artificial que resultan las fronteras lingüísticas de hoy aplicadas a la continuidad ininterrumpida desde los tiempos precolombinos. Así que decidimos aceptar también las voces de las lenguas amerindias del territorio brasileño que lograron entrar en las lenguas europeas a través del portugués (cabe decir que se trata sobre todo de las lenguas de la familia tupí-guaraní cuyos habitantes vivían y siguen viviendo tanto en la parte hispanófona como en la lusófona de Latinoamérica). Aceptamos por lo tanto todas las voces amerindias para las que la lengua intermediaria y la "puerta" a las demás lenguas europeas fueron el español y el portugués y dejamos aparte las voces indígenas de Norteamérica en las que tuvo el papel mediador el inglés o el francés, son palabras como mocasín, tótem, tobogán, etc. (Gómez Capuz, 2004, 28). Por otro lado sí que incluimos la palabra apač 'apache', del actual territorio estadounidense, dado que se trataba del territorio de la Corona española y después de México, hasta mediados del siglo XIX (y los diccionarios ingleses suelen reconocer el papel mediador del español). 
No incluimos las palabras derivadas ni compuestas en eslovaco (kakao 'cacao' $\rightarrow$ kakaovník 'árbol de cacao', miničokoláda de čokoláda 'chocolate, etc.). Tampoco incluimos los nombres propios (Azték 'azteca', etc.), salvo los que se apelativizaron (čivava, tequila, etc.).

Tampoco tienen cabida en el corpus las derivaciones españolas / portuguesas de las bases indígenas, en las que el significado originó en español: habanera 'baile de origen cubano', derivado del nombre de la capital cubana que es de origen arahuaco + el sufijo español de relación -ero, - $a$; pampero 'tipo de viento frío que sopla en las pampas', etc.

La confirmación de la presencia de un indigenismo en el léxico eslovaco es otro de los criterios de su inclusión en el corpus. Para tal evidencia es necesario que la palabra aparezca en los diccionarios normativos elaborados o supervisados por los lingüistas del Instituto Lingüístico de Ludovít Štúr de la Academia de Ciencias Eslovaca (en eslovaco Jazykovedný ústav L'udovita Štúra Slovenskej akadémie vied):

[SCSA] Slovník cudzích slov, akademický, Bratislava, SPN, 2005.

[SSSJ] Slovník súčasného slovenského jazyka. Bratislava: Veda, (se han publicado tres tomos hasta la fecha, A-G en 2006, H-L en 2011 y M-N en 2015).

\section{Adaptación del español al eslovaco}

\subsection{Nivel fonográfico}

En muchos casos los indigenismos, antes de entrar en contacto con el eslovaco, ya se habían sometido al proceso asimilatorio en el nivel fónico dentro de la lengua española: guaraní acuti < español agutí (sonorización) < eslovaco aguti;

Frecuente es la apócope en eslovaco: guayaco > guajak, apache > apač, hamaca > hamak, etc.

En el nivel gráfico se adaptan sobre todo los préstamos más frecuentes: chocolate $>$ čokoláda, caimán > kajman, chihuahua > čivava, etc. Los exotismos y palabras que se han quedado como términos especializados de alcance limitado tienden a mantener la grafía española: henequén, guayacán, cholo, etc.

Hay un grupo relativamente numeroso de préstamos amerindios que presentan las dos formas, la española y la asimilada: quipu / kipu, chicle / čikle, etc.

En algunos de los préstamos recientes se puede ver casos en los que el eslovaco mantiene fielmente la forma indígena (si son términos científicos, de zoología, botánica, 
etc., hay tendencia actual de respetar mucho más la forma original), a diferencia del español donde la palabra suele ser mucho más asimilada debido a la presencia mucho más larga y la frecuencia más elevada, así que se avanzó mucho más en la asimilación del indigenismo en cuestión: ajolote vs. axolotl < nahua axolotl, peyote vs. peyotl < nahua peyotl, chile vs. čili > nahua chilli. En estos casos los diccionarios eslovacos no indican el español como lengua intermediaria y el indigenismo lo toman por préstamo directo (así lo indicamos nosotros también en el corpus).

\subsection{Nivel morfológico}

Algunos préstamos nominales adquieren el género neutro en eslovaco, inexistente en español. Son los sustantivos cuya imagen fonética se parece a los paradigmas neutros del eslovaco. Se trata de nombres inanimados, masculinos en español, que terminan en -o, -e: avokádo, maté, chicle, etc.

El modelo paradigmático eslovaco resulta ser decisivo también en los nombres masculinos en español que terminan en $-a$, lo que es el sufijo prototípicamente femenino en eslovaco: puma, tequila, ambos femeninos en eslovaco. Las terminaciones poco usuales de los indigenismos tienen como resultado la conversión en sustantivos indeclinables en eslovaco, con una forma para todos los casos: kipu, cenote, jaguarundi, kanoe, maté, etc.

Otro fenómeno que se puede observar es que en eslovaco no existe la diferencia sufijal entre la planta y su fruto chirimoyo vs. chirimoya, papayo vs. papaya. El eslovaco coge prestada la forma en - $a$ (čerimoja, papája), la cual desarrolla los dos significados.

\subsection{Nivel semántico}

Si comparamos la riqueza polisémica de los indigenismos en español y en eslovaco, podemos constatar que encontramos sin duda alguna más significados en español.

No obstante, este empobrecimiento semántico es lógico. La mayoría de las palabras del corpus funcionan como exotismos en eslovaco. Son palabras que en la conciencia de los hablantes nativos se asocian a los elementos ajenos a la realidad eslovaca, típicamente se trata de designaciones de animales, vegetales, alimentos o fenómenos geográficos y meteorológicos (Gómez Capuz, 2005, 30). En el caso de los nombres de algunas plantas que, por metonimia, designan también el producto de esta planta, desaparece en eslovaco el significado botánico y se mantiene solo el nombre del producto: henequén 'hilo de agave', maté 'infusión', karnauba 'cera de palma', etc.

Lo que escasea aún más en eslovaco son las acepciones figuradas. Como son exotismos, xenismos, no forman parte de la realidad eslovaca. Los sentidos figurados 
en eslovaco ya se expresan por medio de palabras que designan entidades conocidas, arraigadas en la cultura receptora, por ejemplo:

caimán 'persona astuta que procura salir con sus intentos', en eslovaco es el zorro 'líška' el animal que simboliza dicha característica.

No obstante la diferencia ya se nota también entre el español peninsular y las variantes hispanoamericanas. He aquí algunas acepciones de la palabra coyote que solo se dan en Hispanoamérica y faltan en España: coyote 'persona nacida de padres de distintas razas', 'persona que ayuda a hacer los trámites mediante una remuneración', 'persona que hace operaciones de compra y venta de moneda, descuentos, etc.', 'chismoso, pícaro' ([DA] Diccionario de americanismos, 2010, 687).

Otros ejemplos de sentidos figurados documentados solo en Hispanoamérica:

jaguar, en Chile 'grupo de personas, institución o país que ha conseguido destacar en el ámbito en el que se mueve' (DA, 1202), en eslovaco: tiger

tapir, en Nicaragua 'grupo especial de la policía' (DA, 2014)

aguacate, Costa Rica, El Salvador, Cuba 'persona simplona y poco inteligente' (DA, 54)

Hay muy pocos ejemplos de indigenismos en los que los diccionarios eslovacos ofrezcan una acepción que no forme parte de la estructura semántica del indigenismo en español. La mayoría son significados metonímicos no mencionados explícitamente en los diccionarios españoles, si bien creemos que potencialmente están presentes también en el equivalente español:

jaguár 'coche de marca Jaguar', SSSJ II

ocelot 'piel de ocelote', 'abrigo de pieles de ocelote', SCSA, 687

De la creación metafórica logramos encontrar en los diccionarios normativos eslovacos solamente el caso del coyote. En eslovaco se desarrolló el significado de 'persona cobarde' (SSSJ II, 636).

No obsatnte, en los diccionarios específicos de argot y de jerga figuran más ejemplos de creación semántica independiente de la situación en español.

apač 1. por similitud fonética llega a significar 'apaurin, medicamento de efecto hiponsedativo y ansiolítico' (Oravec, 2014, 16) 2. 'gitano' (Hugo, 2006, 46)1

1 Lo hemos encontrado tan solo en un diccionario checo, pero tanto el checo como el eslovaco comparten dicho significado. 
čokoláda jerga técnica 'pinza de contacto de baquelita, de color marrón' (Oravec, 2014, 38)

lama jerga juvenil 'novato', 'tonto' (Oravec, 1994, 117)

kanibal argot de los prisioneros 'homosexual' (Hugo, 2006, 174)²

\section{Lenguas de origen}

En cuanto al origen de los indigenismos predominan a primera vista cuatro fuentes (más del 78\%). La más numerosa contiene las palabras de la familia de lenguas tupí-guaraní $^{3}$ (25 palabras, 23,58\%). Se hablan en una gran parte del continente sudamericano y es cierto que la mayoría son palabras que se refieren casi exclusivamente a animales o a plantas oriundas de esa región: jaguár, tapír, piraňa, ananás, tukan, etc. Sigue el quechua, la lengua del Imperio inca $(21,19,81 \%)$ que contiene no solamente los nombres de especies naturales, sino también palabras asociadas con la sociedad, productos y tipo de paisaje: lama, kondor, pampa, mita, kaučuk, pita, etc. En tercer lugar se encuentran las lenguas arahuacas, como el taíno, etc., que se hablaban en las Antillas (19, 17,92\%), el espacio geográfico donde se produjo el primer encuentro de los españoles con los habitantes y la realidad del Nuevo Mundo. Por ello encontramos en este grupo los primeros indigenismos: hurikán, kanoe ${ }^{4}$, kanibal, hamak, juka, leguán, papája, etc. El último idioma de los cuatro grandes es el nahua, hablado por los aztecas. Como en el caso del quechua, aquí también hallamos, aparte de las referencias zoológicas y botánicas (avokádo, kojot...), un par de palabras tomadas de la civilización prehispánica de los mexicas, sus alimentos y productos: čokoláda, pulque, etc. El resto son lenguas que aportaron considerablemente menos vocablos (lenguas mayas, caribes, amazónicas y aymara). Y los dos últimos grupos lo forman las lenguas de solo una aportación (guarayo, kuna, lenca, mapuche, mochica, yavapi) y al final los seis indigenismos de etimología incierta, en los que sí se sabe que se trata de etimología amerindia, no obstante no hay unanimidad acerca de la lengua originaria.

A veces (es el caso de varias voces recién introducidas) la lengua intermediara hacia las lenguas europeas puede ser también el inglés o el francés, sin embargo siempre existen estas palabras también en español (o portugués) y provienen de lenguas amerindias habladas en el territorio hispanohablante o lusohablante.

2 Véase la nota de pie anterior.

3 Hemos decidido unirlas en un grupo, ya que no siempre es fácil distinguir, p. ej. un vocablo guaraní de los demás idiomas.

4 La palabra canoa ya la recoge Nebrija (Cano Aguilar, 1988, 253). 


\section{Indigenismos inciertos $y / o$ falsos}

Hay unas cuantas palabras que aparecen clasificadas en los diccionarios eslovacos arriba mencionados como vocablos de etimología amerindia, aunque hay fuentes relevantes que la rechazan o ponen en duda. Mencionemos los más usados:

činčila $f$ (chinchilla) 'mamífero roedor, propio de América del Sur', tradicionalmente se consideraba un préstamo de aymara, pero puede provenir también de chinche 'insecto hemíptero' < latín cìmex (Králik, 2015, 104). Además en España existía una villa con el nombre de Chinchilla en la provincia de Albacete, atestiguada ya en el año 1340 (corpus.rae.es; etimologias.dechile.net)

gaučo $m$ (gaucho) 'habitante de las pampas, hábil jinete, su vida económica se basaba en la cría, aparte de la posible etimología quechua (wahcha 'vagabundo') o mapuche (cauchu 'amigo'), existen varias hipótesis de su posible origen español (de chaucho 'vigilante', vocablo de origen turco), portugués (gaudério) o árabe wahcha 'solitario' (etimologias.dechile.net).

chinín $m$ (quinina) 'alcaloide de quina con ciertas propiedades antimaláricas', puede ser de quechua o del desplazamiento de significado del vocablo español quina 'tipo de resina' < árabe qinna (Králik, 2015, 219)

kolibrík $m$ (colibrí) 'especie de ave tropical derivado de kolibra' $<$ francés $<$ de origen incierto, antes se pensaba que era una palabra antillana (Králik, 2015, 276)

pončo $m$ (poncho) 'prenda de abrigo tradicional de los Andes', español poncho $<$ quechua punchu. Sin embargo, otros lingüistas, como Joan Coromines, niegan su origen indígena, basándose en la aparición de la palabra poncho en español ya en 1530, o sea, antes del primer contacto con los incas (etimologias.dechile.net).

tabak $m$ (tabaco) 'planta, Nicotiniana; polvo de las hojas secas de tabaco', tradicionalmente se consideraba un préstamo de las lenguas antillanas, no obstante hay evidencias de la presencia de la palabra tabaco a principios del siglo XIV, puede ser un posible arabismo tabbāq, tubbāq que se refería a varias hierbas medicinales, que pasó a significar la planta de tabaco (Králik, 2015. 601).

\section{6 Áreas temáticas}

Como se observa en la clasificación temática, predominan los términos que se refieren a las especies animales y vegetales (y sus productos) desconocidas en Europa antes de la llegada de los españoles al continente americano (forman aproximadamente el $71,7 \%$ del corpus): 
plantas y frutos: acapu, ananás, anona, arakača, avokádo, batata, ceiba, čajot, čerimoja, guajak, guajava, juka, kešu, koka, kvinoa, maniok, nopál, papája, pekan, pitanga, ulluco

animales: aguti, anolis, ara, axolotl, čivava, hoacín, huanaco, inia, jabiru, jaguár, jaguarundi, kajman, kapybara, kojot, kondor, kotinga, lama, leguán, matamata, mirikina, nandu, ocelot, paka, pako, pekari, piraňa, pudu, puma, quetzal, tapír, tinama, tukan, uakari, vikuña, viskača, žararaka;

plantas y sus productos ${ }^{5}$ čili, guarana, kasava;

productos vegetales: cigara, havana, henequén, chicle, karnauba, kaučuk, kopal, kuba, kurare, panama, piasava, pita, tampico;

instrumentos y utensilios: hamak, kanoe, maracas, piroga;

alimentos y bebidas: ayahuasca, čiča, čokoláda, kakao, meskal, pulque, tapioka, tequila;

personas y sociedad: apač, caboclo, cholo, kanibal, kasik, katun, kipu, mita;

meteorología: hurikán, orkán, uragán;

productos animales: guáno, vigoñ;

geografía: pampa, puna, savana;

monedas: guaraní, quetzal, lempira;

animales y sus productos: alpaka;

geología: cenote.

\section{Clasificación cronológica}

El primer indigenismo en eslovaco, según el diccionario histórico de la lengua eslovaca $^{6}$ (HSSJ I-VII), es čokoláda (formas antiguas también čukeláda, čukoláda), documentado por primera vez en el siglo XVII (año 1691, HSSJ I, 223).

Encontramos cuatro más en el siglo XVIII: ananás (Králik, 2015, 45), kakao (año 1760; HSSJ II, 11), leguán (1794; HSSJ II, 205), kondor (1798; HSSJ II, 85).

5 Las palabras de este grupo abarcan ambos significados, la de la planta y la del alimento o producto que se hace de ella.

6 Historický slovník slovenského jazyka (en siete tomos), Bratislava, Veda, 1991, 1992, 1994, 1995, 2000, 2005, 2008. Abarca el vocabulario eslovaco antes de la primera codificación del eslovaco por Anton Bernolák a finales del siglo XVIII. 
Y cinco más en el siglo XIX: cigara (Králik, 2015, 94), kanibal (ibidem, 253), kaučuk (ibidem, 263), lama (ibidem, 317), savana (ibidem, 522). En total son 9 indigenismos registrados antes del siglo XX y forman un $8,49 \%$ del corpus.

El resto $(91,51 \%)$ entró en el léxico eslovaco en el siglo XX. Y cabe decir que en el siglo XXI con la creciente globalización del comercio, con el acceso a la información y también gracias al creciente número de eslovacos que viajan a Latinoamérica, crece también la familiaridad con muchos indigenismos que todavía no quedan recopilados en las obras lexicográficas. Se trata sobre todo de los nombres de alimentos y platos típicos: chilaquiles, tamales, guacamole, pachamanca, etc.; o algunos conceptos religiosos y espirituales, drogas vegetales, etc. debido a la nueva religiosidad emergente que se inspira también en las culturas amerindias: mitote, peyote, tzolkin, nagual, tonal, etc.

\section{Conclusión}

Hemos logrado recopilar 106 indigenismos (de las lenguas amerindias de Latinoamérica) en eslovaco según los criterios establecidos. El proceso de asimilación al eslovaco sigue las pautas corrientes. Los términos especializados que se encuentran en la periferia usados solo por los expertos de la disciplina tienden a mantener la grafía española, no asimilada. Se documentan pocos ejemplos de creación semántica dentro de la lengua receptora, dado que los indigenismos son extranjerismos cuyos referentes quedan ajenos a la realidad extralingüística eslovaca. Los casos esporádicos vienen de la capa coloquial y argótica. Por lo que a la lengua de origen se refiere, las primeras cuatro más numerosas (lenguas tupí-guaraní, quechua, arahuaco, nahua) constituyen casi el $80 \%$ de todo el corpus. Temáticamente predominan los referentes vegetales y animales (y productos alimenticios o industriales que aportan) oriundos del continente americano que eran desconocidos en Europa antes de los viajes de Colón. El primer indigenismo que registramos en eslovaco es la palabra čokoláda del año 1691 y junto con otros ocho forman el 8,5\% del corpus de los que tenemos evidencia en el léxico eslovaco antes del siglo XX. El resto se documenta tan solo en el siglo XX y gracias a los contactos crecientes y la facilidad de comunicar y viajar en los últimos años no dudamos que otros indigenismos de Latinoamérica van a encotrar pronto su camino hacia el vocabulario eslovaco.

\section{Apéndice}

En el apéndice incluimos el corpus analizado. Se trata de un corpus entero que presenta todos los indigenismos (introducidos en las lenguas europeas por el español 
y el portugués) encontrados en eslovaco (según los criterios definidos en el capítulo 1) alfabéticamente ordenados. La estructura de la entrada es la siguiente:

- entre corchetes aparece el número de entrada: [2]

- en negrita aparece la entrada: aguti

- en cursiva el género gramatical: $n$

- entre paréntesis la forma española: (agutí)

- sigue el ámbito de uso (siempre y cuando queda especificado en los diccionarios): zool.

- el significado: 'especie de roedor, Dasyprocta, spp'.

- la etimología y entre paréntesis la fuente de información etimológica: < español agutí < guaraní acutí (DA, 64)

- detrás del punto y coma la fuente lexicográfica eslovaca que comprueba la presencia del indigenismo en el léxico eslovaco: SCSA, 22

[1] acapu $n$ (vouacapoua) 'planta con flores de la familia Fabaceae', < lenguas amazónicas del estado de Pará de Brasil (tropicaltimber.info); SCSA, 22

[2] aguti $m$ (agutí) zool. 'especie de roedor, Dasyprocta, spp', < español agutí < guaraní acutí (DA, 64); SCSA, 35

\section{akašu $\rightarrow[52]$ kešu}

[3] alpaka $f$ (alpaca) 1. 'mamífero camélido parecido a la llama, pero más pequeño, Lama pacos' 2. 'pelo de alpaca' 3. 'paño hecho de alpaca', < español alpaca < aymara allpaca (Tirira, 2004, 37); SCSA, 53

[4] ananás $m$ (ananá, piña) 1. 'planta exótica de la familia de las bromeliáceas, Ananas comosus' 2. 'fruta de esta planta', < portugués ananás, forma plural de ananá < naná tupí-guaraní (Králik, 2015, 45; DA, 2010, 110); SSSJ I, 126

[5] anolis $m$ (anolis) zool. 'lagarto de pequeño tamaño, Anolis spp.', < arahuaco (DA, 119); SCSA, 69

[6] anona $f$ (anón) 'árbol de hasta 12 metros de altura, anón, Annona squamosa', < arahuaco (DA, 119); SCSA, 69

[7] apač $m$ (apache) 'bandido o salteador de París y, por extensión, en grandes ciudades', < francés < español americano apache < lengua yavapi, de la tribu yuma de Arizona (etymonline.com); SCSA, 79 
[8] ara $f$ (ara, guacamayo) zool. 'género de aves de la familia de los loros), $<$ creado por el científico francés Bernard Germain de Lacépède en 1799 < portugués arara < tupí a'rara (Ferreira, 1986, 55; ); SCSA, 84

[9] arakača $f$ (arracacha) 'hierba perenne de la familia de las umbelíferas, originaria de América, que crece en tierras frías y cuya raíz tuberosa se come cocida', < quechua rakkacha (DA, 140); SCSA, 85

[10] avokádo $n$ (aguacate) 1. 'árbol de América, de la familia de las lauráceas, Persea americana' 2. 'fruto de este árbol', < español avocado ${ }^{7}<$ nahua ahuacatl (Králik, 2015, 56); SSSJ I, 198

[11] axolotl $m$ (ajolote) zool. 'anfibio urodelo endémico de México de género Ambystoma', < nahua axolotl (rae.es); SCSA, 111

[12] ayahuasca $f$ (ayahuasca) 'bebida de efectos halucinógenos de la planta Banisteriopsis caapi', < quechua aya 'muerto' y huasca 'cuerda'. (DA, 180); SCSA, 112

[13] batata $f$ (batata) bot. 'planta vivaz de la familia de las convolvuláceas, Ipomoea batatas' < español batata < arahuaco (DA, 229); SCSA, 124

[14] caboclo $m$ (caboclo) 'mestizo de blanco con indio', < portugués caboclo < tupí kaa'boc 'persona de piel color cobre' (wordreference.com); SCSA, 155

[15] ceiba $f$ (ceiba) bot. 'árbol tropical, Ceiba pentandra', < español ceiba < arahuaco (DA, 454); SCSA, 159

[16] cenote $m$ (cenote) geol. 'depósito de agua manantial, que se halla en el estado mexicano de Yucatán y otras partes de América', < maya tzonot 'pozo', 'abismo' (DA, 456); SCSA, 160

[17] cigara $^{8} f$ (puro, cigarro) 'cigarro hecho de hojas de tabaco enrollado, liado sin papel' < alemán Zigarre < español cigarro < maya zicer 'hoja de tabaco enrollada' (Králik, 2015, 94); SSSJ I, 428

[18] čajot $m$ (chayote) 1. bot. 'planta trepadora; Sechium edule' 2. 'frutos de esta planta', < español chayote < nahua tzapatli espina + ayotli calabaza (DA, 503); SCSA, 180

7 Es la forma arcaica que surgió por etimología popular al asociar la palabra nahua ahuacatl con la palabra avocado, la forma arcaica de abogado. Hoy en día el nombre de la planta y su fruto es aguacate (Králik, 2015, 56).

8 La palabra cigareta 'cigarrillo' muestra la intermediación francesa con el sufijo diminutivo de la lengua gala (Králik, 2015, 94). 
[19] čerimoja $f$ (chirimoya) bot. 'árbol de la familia de las anonáceas, chirimoyo; fruto del chirimoyo, chirimoya', < español chirimoya < quechua chirimuya 'semillas frías' (Morton, 1987, 65); SCSA, 181

[20] čiča $f$ (chicha) 'bebida alcohólica fermentada, tradicional en México y Centroamérica', < español chicha < kuna (lengua de una tribu de Panamá y de Colombia) chichab 'maíz' (rae.es); SCSA, 181

[21] čili $m$ (chile) 1.'variedad de pimiento picante' 2. 'pimienta molida de los frutos de esta planta' < español chile < nahua chilli (Králik, 2015, 104); SSSJ I, 507

[22] čivava $f$ (perro chihuahua) 'raza de perro', < español chihuaha, nombrada según la región mexicana de Chihuahua < topónimo de origen nahua o taramura (web.archive.org); SSSJ I, 521

[23] čokoláda $f$ (chocolate) 1. 'pasta hecha con cacao y azúcar molidos' 2. 'bebida que se hace de chocolate' 3. 'color de la piel bronceada', < español chocolate < alemán Schokolade < nahua chocolatl (Králik, 2015, 106; HSSJ I, 222-223); SSSJ I, 532

[24] guajak $m$ (guayaco) bot. árbol tropical, Guayacum officinale', < español guayaco, acortado de guayacán < arahuaco waiakan (DA, 1096); SCSA, 358

[25] guajava $f$ (guayaba) 1. bot. 'árbol de América, Psidium guayava' 2. 'su fruto' < arahuaco guayabo (DA, 1094); SSSJ I, 1097

[26] guáno $n$ (guano) 'materia excrementicia de aves marinas', < español guano < quechua wánu ,abono' (DA, 1079); SSSJ I, 1097

[27] guarana $f$ (guaraná) 'arbusto trepador de la familia Sapindaceae, Paullinia cupana' 2. 'bebida estimulante de las semillas de este arbusto', < español guaraná < tupí-guaraní warana 'fruta como los ojos de las personas' (merriamwebster.com) o la apelativización del nombre de la tribu guaraní (SCSA, 358); SSSJ I, 1097

[28] guaraní $n$ (guaraní) fin. 'moneda nacional de Paraguay', < español guaraní, según los habitantes indígenas de Paraguay; SCSA, 358

[29] hamak $m$ (hamaca) 'red colgada que sirve de cama y columpio, hamaca', < español hamaca < arahuaco (DA, 1131); SSSJ II, 42

[30] henequén $m$ (henequén) 'hilo que se hace de las hojas de henequén, Agavaceae', < español henequén < maya (rae.es); SCSA, 372

[31] havana $f$ (habano) 'cigarro puro de Cuba', < español habano, nombre deriva de un cacique taíno llamado Habaguanex (etimologia.dechile.net); SCSA, 367 
[32] hoacín $m$ (hoatzin) 'ave tropical Opisthocomus hoazin', < español hoatzin < nahua huāctzīn, huāhtzīn (wordreference.com); SCSA, 379

[33] huanaco $m$ / guanako $n$ (huanaco, guanaco) 'mamífero camélido, muy parecido a la llama, Lama guanicoe', < español guanaco, huanaco < quechua wanaku (DA, 1077); SCSA, 386

[34] hurikán $m$ (huracán) 'viento de forma impetuosa, a modo de torbellino huracán', < inglés hurricane < español huracán < arahuaco hurakán 'tormenta fuerte'(Králik, 2015, 213); SSSJ II, 218

[35] chicle, čikle $n$ (chicle) 'gomorresina que fluye del tronco del árbol de chicozapote', < español chicle < náhautl tzictli, de tzicoa 'pegar' (DA, 517); SCSA, 402

[36] cholo $m$ (cholo) 'mestizo entre indios y criollos o entre indios y mestizos', < español cholo < mochica cholu 'muchacho, joven' (derecho.usmp.edu.pe); SCSA, 405

[37] inia $f$ (inia) zool. 'delfín amazónico, de género Inia', < guarayo (Tirira, 2004, 84); SCSA, 429

[38] jabiru $m$ (yabirú, jabirú) zool. 'cigüeña, Jabiru mycteria', español yabirú, jabirú < guaraní (DA, 2183); SCSA 435

[39] jaguár $m$ (jaguar) 'felino americano, Panthera onca', portugués / francés jaguar < tupí yaguará (rae.es); SSSJ II, 429

[40] jaguarundi $f$ (yaguarundí) zool. 'felino del tamaño de un gato, Puma yagouaroundi, < guaraní yaguarundí (DA, 2185); SCSA, 455

[41] juka (yuca) bot. 'planta de América tropical, de la familia de las liliáceas, Manihot esculenta', español yuca < arahuaco (rae.es); SSSJ II, 481

[42] kajman $m$ (caimán) zool. 'reptil parecido al cocodrilo, del género Caiman', < español caimán < arahuaco kaimán (rae.es); SSSJ II, 497

[43] kakao $n$ (cacao) 1. 'polvo del árbol de cacao' 2. 'bebida de él', < español cacao < nahua cacáhu(tl) (Králik, 2015, 249); SSSJ II, 498

[44] kanibal $m$ (caníbal) 1. 'antropófago' 2. 'persona cruel', < español caníbal < arahuaco caniba (Králik, 2015, 253); SSSJ II, 520

[45] kanoe $n$ (canoa) 'embarcación de remo', < inglés canoe < español canoa < arahuaco (Králik, 2015, 253); SSSJ II, 521

[46] kapybara $f$ (capibara) 'roedor americano acuático Hydrochoreus hydrochaeris', < tupí (Tirira, 2004, 187); SCSA, 476 
[47] karnauba $f$ (carnaúba) 'cera de la palmera brasileña Copernicia prunifera', < portugués carnaúba < tupí karana’iwa (wordreference.com); SCSA, 481

[48] kasava / kasave $f$ (cazabe) 'arbusto del género Manihot; tubérculos de este arbusto; tortita elaborada con harina de yuca', < español cazabe < arahuaco cazabí 'pan de yuca' (rae.es); SCSA, 484

[49] kasik $m$ (cacique) hist. 1. 'jefe indio' 2. 'político regional influyente', < español cacique < arahuaco cacike, probablemente de arahuaco kassequa 'jefe' (DA, 4) o del maya cah 'mano, símbolo de autoridad' + tsic 'obedecer' (Partridge, 2006, 3006); SCSA, 484

[50] katun $m$ (katún) 'ciclo del calendario maya, equivalente a 7200 días', maya k'atun (SCSA, 489); SCSA, 489

[51] kaučuk $m$ (caucho) 'goma elástica de un árbol tropical, Hevea brasiliensis' < español cauchuc $/$ francés caoutchouc < quechua kawchu (DA, 447); SSSJ II, 559

[52] kešu $m$ (cajú, anacardo, marañón) alim. 'nuez de un árbol originario de la región amazónica del nordeste de Brasil y de Venezuela', acortamiento del francés acajou < portugués acajú < tupí acajuba (etymonline.com); SSSJ II, 573

[53] kipu / quipu $n$ (quipu) 'cuerdas anudadas usadas por los indios del Perú como sistema de contabilidad y tal vez de comunicacón', < español quipu < quechua quipu ,nudo' (rae.es); SCSA, 457

[54] kojot $m$ (coyote) 1. zool. 'mamífero carnívoro de Norteamérica, Canis latrans' 2. 'persona cobarde y malintencionada', < español coyote < nahua coyotl (DA, 687); SSSJ II, 636

[55] koka $f$ (coca) 1. bot. 'arbusto, Erythroxylon coca' 2. 'hojas de coca', < español coca < aymara cuca, coca, (Králik, 2015, 274); SSSJ II,636

[56] kondor $m$ (cóndor) 'ave rapaz de los Andes, Vultur gryphus, < español cóndor < quechua cúntur (rae.es); SSSJ II, 686

[57] kopal $m$ (copal) 'resina casi incolora, muy dura y sin olor ni sabor del árbol Bursera spp., < español copal < nahua copalli resina (DA, 660); SCSA, 538

[58] kotinga $f$ (cotinga) zool. 'ave tropical Cotingidae', < tupí (wordreference. com); SCSA, 546

[59] kuba $f$ (puro cubano) 'puro de tabaco cubano, cuadrado y de mediana calidad', < arahuaco; SCSA, 556

9 Hoy en día en español se usa la palabra caucho. 
[60] kurare $m$ (curare) farm., quím. 'veneno extraído de varias especies de plantas', $<$ español curare < lenguas caribes wurali o wurari (etymonline.com); SSSJ II, 856

[61] kvinoa / quinoa $f$ (quinoa) bot. 'planta anual, Chenopodium quinoa; semillas comestibles de esta planta', < quechua kinúwa o kínua (DA, 1805); SCSA, 566

[62] lama $f$ (llama) zool. 'mamífero camélido doméstico, Lama glama', < quechua llama (Tirira, 2004, 37); SSSJ II, 908

[63] leguán $m$ (iguana) zool. 'reptil parecido al lagarto, Iguanidae', español iguana $<$ arahuaco (DA, 1175); SSSJ II, 942

[64] lempira $f$ (lempira) 'moneda nacional de Honduras', < español lempira < nombre del jefe indio Lempira, de la tribu de los lencas, famoso por su lucha contra los españoles (rae.es); SCSA, 580

[65] maniok $m$ (mandioca) bot. 'arbusto tropical; tubérculos de este arbusto', < guaraní mandiog (DA, 1365); SSSJ III, 81

[66] maracas $m p l$. (maracas) mús. 'instrumento musical consistente en calabazas con granos o chinas en su interior', < guaraní mbaraca (rae.es); SCSA, 612

[67] matamata $f$ (matamata) zool. 'tortuga, Chelus fimbriatus', < lenguas amazónicas; SCSA, 616

[68] maté $n$ (mate) merc. 'infusión de la planta yerba mate, Ilex paraguariensis', < español mate < quechua mati 'calabacita' (DA, 1403); SSSJ III, 117

[69] meskal $m$ (mezcal) merc. 'aguardiente de agave', < español mezcal 'aguardiente de agave' < nahua metl maguey + (i)xcalli (DA, 1432); SCSA, 626

[70] mirikina $f$ (mirikiná) zool. 'especie de mono, Aotus vociferans', < guaraní (Tirira, 2004, 168); SCSA, 641

[71] mita $f$ (mita) 'trabajos públicos forzados en Hispanoamérica en los tiempos de colonia', < quechua mit'a 'turno', 'semana de trabajo' (rae.es); SCSA, 641

[72] nandu $m$ (ñandú) zool. 'ave corredora americana, ñandú, Rhea americana', < español ñandú < guaraní ñandú (DA, 1515); SSSJ III, 598

[73] nopál $m$ (nopal) bot., hort. 'planta de la familia de las cactáceas, Opuntia ficus-indica', español nopal < nahua nopalli (DA, 1507); SSSJ III, 1039

[74] ocelot $m$ (ocelote) 1. zool. 'felino americano Leopardus pardalis' 2. 'piel de ocelote', español ocelote < francés ocelot < nahua ocelotl 'tigre' (DA, 1526); SCSA, 687 
[75] orkán $m$ (huracán) 'viento (sub)tropical devastador', alemán Orkan < holandés orkaan < español huracán (Králik, 2015, 407; SCSA, 702), véase más en [34] hurikán; SCSA, 702

[76] paka $f$ (paca) 'especie de roedor Cuniculus paca', < quechua pakpaka, de origen onomatopéyico (DA, 1549); SCSA, 711

[77] pako (paco) 'Lama pacos', < quechua paku (DA, 1553); SCSA, 711

[78] pampa $f$ (pampa) 'llanura extensa de América del Sur sin vegetación arbórea', español pampa < quechua pampa 'llano, llanura', (DA, 1578); SCSA, 715

[79] panama $f$ (panamá) 1. 'tela de hilos guesos' 2. 'sombrero de jipijapa' 3. 'escándalo', panamá < Panamá, topónimo indígena; SCSA, 715

[80] papája $f$ (papaya) bot. 1. 'árbol de la familia de las caricáceas, papayo, Carica papaya' 2. 'fruto de este árbol, papaya', español papaya < arahuaco (DA, 1592); SCSA, 718

[81] pekan $m$ (pacano, pecán; pacana) 1. árbol caducifolio, Carya illinoinensis' 2. 'nuez de este árbol', < nahua (rae.es); SCSA, 737

[82] pekari $m$ (pekari) zool. 'especie de saíno, de familia Tayassuidae', < guaraní (DA, 1636); SCSA, 737

[83] piasava $f$ (piasaba) 'fibra de la piasaba, Aphandra natalia', < portugués piaçaba $<$ tupí (wordreference.com); SCSA, 751

[84] piraja / piraňa $f$ (piraña) zool. 'peces carnívoros sudamericanos, subfamilia Serrasalminae', < portugués pirnaha < tupí pi'rãia, compuesto de pira 'pez' y ãia 'dientes', (rae.es); SCSA, 755

[85] piroga $f$ (piragua) 'embarcación larga y estrecha, hecha de una pieza', < lenguas caribes (rae.es); SCSA, 755

[86] pita $f$ (pita) text. 'fibra de maguey', < español pita < quechua pita (wordreference. com); SCSA, 755

[87] pitanga $f$ (pitanga) bot. 'arbusto tropical, Eugenia uniflora', < portugués pitanga < tupí pïtanga 'amarrilento' (wordreference.com); SCSA, 755

[88] pudu $m$ (pudú) zool. 'cérvido pequeño', < mapuche pudu (rae.es); SCSA, 812

[89] pulque / pulke $n$ (pulque) 'bebida fermentada de agave', < español pulque < nahua, apócope de poliuhqui-octli vino podrido (DA, 1781); SCSA, 812 
[90] puma (puma) $f$ 'felino americano, Puma concolor', < español puma $<$ quechua puma, poma, (Králik, 2015, 484); SCSA, 813

[91] puna $f$ (puna) geogr. 'tierra alta, próxima a la cordillera de los Andes', < quechua (DA, 1782); SCSA, 813

[92] quetzal $m$ (quetzal) 1. zool. 'ave tropical, Pharomachrus moccino' 2. 'moneda nacional de Guatemala', < español quetzal < nahua quetzalli 'hermosa pluma' (DA, 1802); SCSA, 818

[93] savana $f$ (sabana) geogr. 'llanura dilatada sin árboles', < español sabana < caribe (rae.es); SCSA, 862

[94] tapioka $f$ (tapioca) merc. 'fécula que se extrae de la raíz de la mandioca', < portugués tapioca < tupí tïpiok 'residuo', 'coágulo' (rae.es); SSCA, 942

[95] tampico / tampiko $n$ (fibra de tampico, istle) text. 'fibra de agave y yuca', < según la ciudad mexicana de Tampico, de origen huasteco (una de las lenguas maya), tam-piko 'lugar de nutrias'; SCSA, 940

[96] tapír $m$ (tapir) zool. 'herbívoro tropical, del género Tapirus', < español tapir < tupí tapira (Králik, 2015, 604); SCSA, 942

[97] tequila $f$ (tequila) alim. 'aguardiente de agave azul', < español tequila, nombrado según la ciudad de Tequila en Jalisco, México, topónimo de origen nahua tecuila 'lugar de tributo'; SCSA, 952

[98] tinama $f$ (tinamú) 'ave gallinácea caminadora, Tinamidae tinamú', < kariña, lengua caribe (Gotch, 1995, 182); SCSA, 963

[99] tukan $m$ (tucán) zool. 'ave americana trepadora, de la familia Ramphastidae', < español tucán < tupí-guaraní tucã, tucana (rae.es); SCSA, 991

[100] uakari $m$ (guacarí, uakarí) zool. 'primate platirrino de género Cacajao', < tupí (wordreference.com); SCSA, 998

[101] ulluco (ulluco, ullucu) bot. 'planta herbácea Ullucus tuberosus', < quechua ulluku (DA, 2117); SCSA, 998

[102] uragán $m$ (huracán) meteor. 'viento devastador', francés ouragan < español huracán (Králik, 2015, 643), véase más en [34] hurikán; SCSA, 1003

[103] vigoň $f$ (vicuña) 'lana de vicuña', francés vigogne < español vicuña, véase más en [104] vikuňa; SCSA, 1019 
[104] vikuňa $f$ (vicuña) zool. 'mamífero camélido, Vicugna vicugna', español vicuña $<$ quechua vicunna (DA, 2175); SCSA, 1020

[105] viskača $f$ (vizcacha) zool. 'roedor de los chinchíllidos Lagostomus maximus', español vizcacha < quechua wisk'acha (wordreference.com); SCSA, 1022

[106] žararaka $f$ (yarará, jararaca) zool. 'serpiente venenosa, del género Bothrops', $<$ portugués jararaca < tupí yararaca 'serpiente grande' (definiciona.com); SCSA, 1035

\section{Bibliografía}

Cano Aguilar, R., El español a través de los tiempos, Madrid 1988.

[DA] Diccionario de americanismos, Madrid 2010.

Ferreira, A., Novo Dicionário da Língua Portuguesa, Rio de Janeiro 1986.

Gómez Capuz, J., Préstamos del español, Madrid 2004.

Gómez Capuz, J., La inmigración léxica, Madrid 2005.

Gotch, A. F., „Tinamous“. Latin Names Explained. A Guide to the Scientific Classifications of Reptiles, Birds \& Mammals, London 1995.

[HSSJ I] Majtán, M. et al., Historický slovník slovenského jazyka I (A-J), Bratislava 1991.

[HSSJ II] Majtán, M. et al., Historický slovník slovenského jazyka II (K-N), Bratislava 1992.

Hugo, J. (ed.), Slovník nespisovné češtiny, Praha 2006.

Králik, L., Stručný etymologický slovník slovenčiny, Bratislava 2015.

Morton, J., Cherimoya, en: Fruits of Warm Climates, Miami 1987, pp. 65-69.

Oravec, P., Slovník slangu a hovorovej slovenčiny, Praha 2014.

Partridge, E., Origins. A Short Etymological Dictionary of Modern English, London 2006.

[SCSA] Petráčková, V., Kraus, J (ed.), Slovník cudzích slov (akademický), Bratislava 2005.

[SSSJ I] Buzássyová, K., Jarošová, A. (eds.), Slovník súčasného slovenského jazyka I (AG), Bratislava 2006.

[SSSJ II] Buzássyová, K., Jarošová, A. (eds.), Slovník súčasného slovenského jazyka II (H-L), Bratislava 2011.

Tirirá, D., Nombres de los mamíferos del Ecuador, Quito 2004. 


\section{Fuentes electrónicas}

Archive.org: [en línea], web.archive.org/web [25. 9. 2017].

Definición y etimología. Definiciona: [en línea], https://definiciona.com/ [25. 9. 2017].

Diccionario de la lengua española: [en línea], http://dle.rae.es/?w=diccionario [25. 9. 2017].

Diccionario Etimológico español en línea: [en línea], http://etimologias.dechile.net/ [25. 9. 2017].

Merriam-Webster: [en línea], https://www.merriam-webster.com/ [25. 9. 2017].

Online etymology dictionary: http://etymonline.com/ [25. 9. 2017].

Portal Jurídico - Facultad de Derecho - USMP: [en línea], http://www.derecho.usmp. edu.pe/itaest2013/diciembre_2013/miscelanea_02.htm [25. 9. 2017].

Tropical Timber: [en línea], http://www.tropicaltimber.info/ [25. 9. 2017].

WordReference.com: [en línea], www.wordreference.com [25. 9. 2017]. 


\section{Bohdan Ulašin}

\section{Iberoameriške indijanske besede v slovaščini}

Ključne besede: indijanska beseda, jeziki ameriških Indijancev, slovaščina, španščina, semantična tvorba, kronologija

Prispevek preučuje prisotnost izposojenk, ki izvirajo iz jezikov ameriških Indijancev, v slovaščini, pri kateri je španščina (ali portugalščina), prav tako kot pri drugih evropskih jezikih, pri prevzemanju besed delovala kot prvi evropski vmesni jezik. Avtor določi kriterije za izbiro besed in oblikuje izčrpen korpus vseh tovrstnih izposojenk, ki se pojavljajo v izbranih uglednih delih slovaškega slovaropisja. Skupno je gesel 106. Nato jih prouči in razvrsti glede na njihov proces prilikovanja ter pri tem opiše ustaljene in najpogostejše spremembe na različnih ravneh: izvor - skoraj štiri petine korpusa izvira iz štirih glavnih virov (skupine tupijsko-gvaranskih jezikov, jezika kečua, aravakanskih jezikov in jezika náhuatl); tematsko področje (popolna prevlada specifičnih geografskih značilnosti Novega sveta ter v Evropi nepoznanih botaničnih in živalskih vrst); kronologijo pojavitve (prva je bila beseda čokoláda »čokolada«, ki se je v pisni obliki prvič pojavila leta 1691) in semantični razvoj v slovaškem jeziku, ki v španščini nima vzporednic. Proces izposojanja besed iz jezikov ameriških Indijancev se še ni končal. V današnjem povezanem in globaliziranem svetu lahko opazujemo nove izposojenke, ki v slovarjih sicer še niso zavedene, vendar so se kljub temu ustalile v slovaškem besedišču. Ponavadi gre za gastronomske izraze in verske pojme. 


\section{Bohdan Ulašin}

\section{Ibero-American Amerindian Loanwords in Slovak}

Keywords: indigenous loanword, Amerindian languages, Slovak, Spanish, semantic creation, chronology

The article examines the presence of loanwords of Amerindian origin in Slovak, in which Spanish (or Portuguese) acted as the first European intermediate language for all the other European languages. The criteria for their inclusion are presented, and an exhaustive corpus of all such loanwords found in selected prestigious works of Slovak lexicography is thus formed. The total number of entries is 106. These are then analysed and classified in terms of assimilation processes: regularized and most frequent changes on different levels are shown; origin: almost four fifths of the corpus comes from four major sources (Tupi-Guarani languages Quechua, Arawakan languages and Nahuatl); thematic area (an absolute prevalence of specific New World geographical features and botanical and animal species unknown in Europe); chronology of occurrence (the first being the word čokoláda 'chocolate', the earliest written occurrence of which dates from 1691) and semantic development in the Slovak language, which does not have a parallel in Spanish. Moreover, the process of borrowing Amerindian loanwords has not finished. In today's connected and globalized world we can observe new loanwords that do not yet appear in dictionaries, although they have already settled in the Slovak lexicon. These usually refer to gastronomic or religious concepts. 